\title{
Evidence for Altered NMDA Receptor Function as a Basis for Metaplasticity in Visual Cortex
}

\author{
Benjamin D. Philpot, Juan S. Espinosa, and Mark F. Bear \\ Howard Hughes Medical Institute and The Picower Center for Learning and Memory, Department of Brain and Cognitive Sciences, Massachusetts Institute \\ of Technology, Cambridge, Massachusetts 02139
}

\begin{abstract}
Sensory deprivation alters the properties of synaptic plasticity induced in the superficial layers of the visual cortex, facilitating long-term potentiation and reducing long-term depression (LTD) across a range of stimulation frequencies. Available data are compatible with either a downregulation of the mechanisms of LTD or an upregulation of NMDA receptor function in the visual cortex of dark-reared animals. Here, we provide evidence for enhanced NMDA receptor function by showing that deprivation produces a horizontal shift in the frequency-response function, decreasing LTD in response to $1 \mathrm{~Hz}$ stimulation, but increasing LTD in response to $0.5 \mathrm{~Hz}$ stimulation. In addition, we show that the effects of dark-rearing on the frequency dependence of LTD can be reversed acutely by partial NMDA receptor blockade. Finally, we show that an in vivo manipulation that rapidly downregulates NMDA receptor function in the visual cortex, brief light exposure, also rapidly reverses the effect of dark-rearing on LTD.
\end{abstract}

Key words: NMDA receptor; metaplasticity; BCM theory; dark rearing; APV; visual cortex

\section{Introduction}

NMDA receptor-dependent long-term depression (LTD) is induced by a protein phosphatase cascade that is activated in response to a defined range of postsynaptic $\left[\mathrm{Ca}^{2+}\right]_{\mathrm{i}}$ (Kirkwood and Bear, 1994; Mulkey et al., 1994; Cummings et al., 1996; Neveu and Zucker, 1996). In neocortex and hippocampus, presynaptic stimulation at $1 \mathrm{~Hz}$ is often sufficient to provide a level of NMDA receptor activation that is optimal for inducing LTD. Stronger NMDA receptor activation, produced by increased stimulation frequencies, triggers protein kinases and yields progressively less LTD until long-term potentiation (LTP) is induced instead. In contrast, at stimulation frequencies below $1 \mathrm{~Hz}$, summation of $\mathrm{Ca}^{2+}$ responses diminishes until no LTD is induced at all (for review, see Bear and Abraham, 1996).

The stimulation frequency dependence of synaptic plasticity in the visual cortex depends on the history of sensory experience. Kirkwood et al. (1996) showed that LTP can be elicited with lower stimulation frequencies in the visual cortex of dark-reared rats as compared with visually experienced animals. Moreover, the magnitude of LTD after $1 \mathrm{~Hz}$ stimulation is greatly reduced after dark-rearing. Because the balance of LTP and LTD is believed to be critical for the experience-dependent development of cortical

Received Jan. 14, 2003; revised April 22, 2003; accepted April 24, 2003.

This work was supported in part by Howard Hughes Medical Institute and grants from the National Institutes of Health, National Science Foundation, and Human Frontiers Science Project (to M.F.B.) as well as the Whitehall Foundation (to B.D.P.). We thank E. Sklar and S. Meagher for assistance, Rob Crozier and Fleur Kidd for critical reading of this manuscript, and Cheng-Hang Liu and Harel Shouval for helpful discussions.

Correspondence should be addressed to Dr. Mark F. Bear, Howard Hughes Medical Institute and The Picower Center for Learning and Memory, Department of Brain and Cognitive Sciences, Massachusetts Institute of Technology, 77 Massachusetts Avenue, E19-351, Cambridge, MA 02139. E-mail: mbear@mit.edu.

J. S. Espinosa's present address: Department of Neurobiology, Stanford University School of Medicine, Sherman Fairchild Science Building, 299 West Campus Drive, Stanford, CA 94305-5125.

Copyright $\odot 2003$ Society for Neuroscience $\quad$ 0270-6474/03/235583-06\$15.00/0 circuits (Katz and Shatz, 1996; Bear, 1998), the mechanism of this type of metaplasticity is a question of some importance.

One possible explanation for the data of Kirkwood et al. (1996) is that LTD mechanisms are downregulated in the absence of visual experience. A selective loss of LTD (e.g., by reduced synaptic expression of protein phosphatases) would be expected to produce a vertical shift in the frequency-response function (Fig. 1A). An alternative hypothesis is that NMDA receptormediated synaptic transmission is enhanced after a period of dark-rearing. Such a modification would be expected to shift the frequency-response function horizontally (Fig. $1 B$ ), moving the optimal stimulation for LTD to a lower frequency. Although mechanistically quite distinct, either of these modifications could account for the available data (Fig. 1). One simple way to distinguish among these alternatives is to explore the effects of visual deprivation and experience on LTD induced by stimulation frequencies lower than $1 \mathrm{~Hz}$.

Here, we provide evidence that dark-rearing produces a horizontal shift in the LTD frequency-response relationship and that this can be reversed acutely by partial blockade of NMDA receptors. Moreover, we show that briefly exposing dark-reared animals to light, which has been shown to rapidly reduce the duration of NMDA receptor-mediated excitatory postsynaptic currents (EPSCs) (Philpot et al., 2001a), also rapidly shifts the frequency dependence of LTD. Taken together, the data support the hypothesis that altered NMDA receptor function is a basis for metaplasticity in the visual cortex.

\section{Materials and Methods}

Subjects. Long Evans rats between the ages of P21 and P31 were raised with a varied history of light exposure (LE) and fed ad libitum. Control light-reared rats were raised on a 12/12 hr light/dark cycle, whereas darkreared rats were raised in complete darkness. LE was achieved by bringing a dark-reared rat into the light for $2 \mathrm{hr}$. 
A

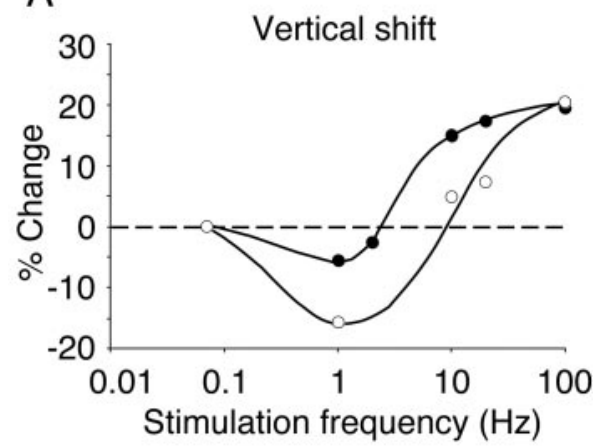

B

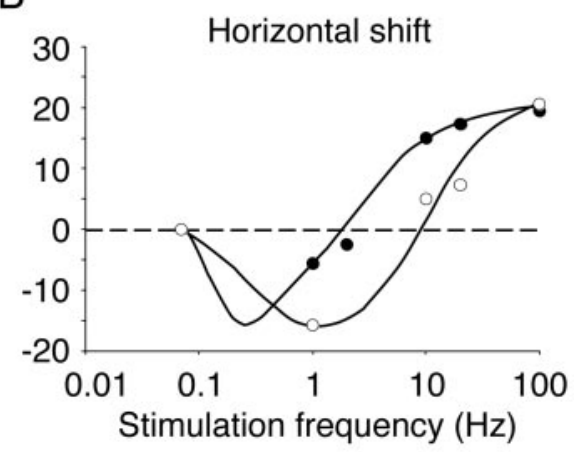

Figure 1. Alternative models for how visual experience can modify the frequency-response function measured in layers $2 / 3$ and evoked by layer 4 stimulation in the slice preparation. $A$, In a vertical shift of the frequency-response function, LTD is difficult to induce with low frequencies of stimulation in the cortex of dark-reared animals (filled symbols) as compared with the cortex of normal, light-reared animals (open symbols). B, In a horizontal shift, substantial LTD can be induced in dark-reared cortex at very low frequencies of stimulation. Data points are adapted from Kirkwood et al. (1996).

Cortical slice preparation. Rats were given a lethal dose of barbiturates and then rapidly decapitated after the disappearance of corneal reflexes in compliance with the U.S. Department of Health and Human Services and Brown University guidelines. The visual cortex was isolated in an ice-cold dissection buffer $(212.7 \mathrm{~mm}$ sucrose, $2.6 \mathrm{~mm} \mathrm{KCl}, 1.23 \mathrm{~mm}$ $\mathrm{NaH}_{2} \mathrm{PO}_{4}, 26 \mathrm{~mm} \mathrm{NaHCO}, 10 \mathrm{~mm}$ dextrose, $3 \mathrm{~mm} \mathrm{MgCl}_{2}$, and $1 \mathrm{~mm}$ $\mathrm{CaCl}_{2}$, saturated with $95 \% \mathrm{O}_{2}$ and $\left.5 \% \mathrm{CO}_{2}\right)$. Coronal sections $(400 \mu \mathrm{M})$ were cut as described previously (Kirkwood et al., 1993) using a vibrating microtome (DSK microslicer; or Leica VT1000S, Leica, Nussloch, Germany). Slices were left to recover for an hour in an incubation chamber filled with warmed $\left(\sim 30^{\circ} \mathrm{C}\right)$ artificial CSF (ACSF; $124 \mathrm{~mm} \mathrm{NaCl}, 5 \mathrm{~mm}$ $\mathrm{KCl}, 1.25 \mathrm{~mm} \mathrm{Na}_{2} \mathrm{PO}_{4}, 26 \mathrm{~mm} \mathrm{NaHCO}_{3}, 1 \mathrm{~mm} \mathrm{MgCl}, 2 \mathrm{~mm} \mathrm{CaCl}_{2}$, and $10 \mathrm{~mm}$ dextrose, saturated with $95 \% \mathrm{O}_{2}$ and $5 \% \mathrm{CO}_{2}$ ) and then kept at room temperature until use.

Extracellular electrophysiology. Slices were transferred to an interface recording chamber maintained at $30^{\circ} \mathrm{C}$ and perfused with ACSF at a rate of $2.5 \mathrm{ml} / \mathrm{min}$. A stimulation electrode (concentric bipolar tungsten) was positioned in layer 4 , and a glass recording electrode $(\sim 1 \mathrm{M} \Omega)$ filled with ACSF was positioned in layers $2 / 3$. The magnitude of responses evoked by a $200 \mu$ s pulse was monitored by the amplitude of the field potential (FP). Stimulation intensity was adjusted to elicit half the maximal response, and stable baseline responses were elicited every $30 \mathrm{sec}$. The resulting signals were filtered between 0.1 and $3 \mathrm{kHz}$, amplified 1000 times, and captured at $10 \mathrm{kHz}$ on an IBM-compatible computer using Experimenter's Workbench software (DataWave Technologies Corp.). After achieving a stable baseline ( $<4 \% \mathrm{drift})$ for $15-30 \mathrm{~min}$, slices were stimulated with 900 pulses either at 1 or $0.5 \mathrm{~Hz}$. FP amplitudes were recorded every $30 \mathrm{sec}$ for $40 \mathrm{~min}$ after the cessation of the stimulation protocol. Control and experimental subjects were run in an interleaved manner. The data were normalized, averaged, and reported as means \pm SEM. Changes in synaptic strength were measured by comparing the average response amplitude $30-40 \mathrm{~min}$ after conditioning stimulation to the preconditioning baseline response.

Statistics. All data were collected so that each test condition involved two groups that were run in an interleaved manner. Therefore, $t$ tests were used to test for statistical significance, placed at $p<0.05$. Data are expressed as means \pm SEM.

\section{Results \\ Effects of low-frequency stimulations in light-reared and dark-reared cortex}

To address the manner in which experience modifies the properties of synaptic depression in layer $4-2 / 3$ connections, we compared the consequences of 0.5 and $1 \mathrm{~Hz}$ stimulation on FP amplitude in light-reared and dark-reared cortex. We discovered that $30 \mathrm{~min}$ of $0.5 \mathrm{~Hz}$ stimulation induced significantly greater LTD in the visual cortex of dark-reared rats compared with lightreared rats (light-reared: $92 \pm 2 \%$ of baseline, $n=8$; dark-reared: $80 \pm 5 \%$ of baseline, $n=7 ; p<0.02$; Fig. $2 A$ ). In contrast, 15 min of $1 \mathrm{~Hz}$ stimulation evoked significantly greater synaptic depression in the visual cortex of light-reared rats compared with the visual cortex of dark-reared rats (light-reared: $78 \pm 2 \%$ of baseline, $n=15$; dark-reared: $88 \pm 4 \%$ of baseline, $n=10$; $p<0.02$; Fig. $2 B$ ). The finding that synaptic depression induced by $1 \mathrm{~Hz}$ stimulation is attenuated in deprived cortex verifies previous findings by Kirkwood et al. (1996). These data demonstrate that rearing conditions alter the properties of synaptic plasticity by horizontally shifting the frequency-response function.

Although our schematic depicts a static LTD threshold (Fig. $1 B$ ), we cannot rule out the possibility that visual deprivation and experience alter this as well. In fact, theoretical analysis indicates that both the LTP and LTD thresholds will be shifted by altered NMDA receptor effectiveness (Castellani et al., 2001; Shouval et al., 2002). However, these experiments are not technically feasible using our approach of varying stimulation frequency. For example, a $0.2 \mathrm{~Hz}$ induction protocol would take $75 \mathrm{~min}$ if the number of stimulation pulses is held to 900 . Given the necessary long baseline and induction periods, it would be difficult, if not impossible, to detect subtle differences in LTD near threshold. However, it should be noted that there is experimental support using evoked responses paired with depolarization that the LTD voltage threshold can also be modified (Ngezahayo et al., 2000).

\section{Effects of partial NMDA receptor blockade on LTD induced by low-frequency stimulations}

The observed shift in the frequency-response function could be accounted for by enhanced NMDA receptor function in the visual cortex of dark-reared rats. We, therefore, asked whether a slight reduction in NMDA receptor function might reverse the effects of dark-rearing on LTD. Previously, we demonstrated that $1 \mu \mathrm{M}$ APV provides a partial blockade ( $20 \%)$ of NMDA receptors in the visual cortex (Philpot et al., 2001a), so we investigated how this treatment alters the stimulation-frequency dependence of LTD in dark-reared animals.

Perhaps not surprisingly, the magnitude of LTD evoked by 0.5 $\mathrm{Hz}$ stimulation in dark-reared rats was reduced when $1 \mu \mathrm{M} \mathrm{APV}$ was applied during the stimulation period (dark-reared: $77 \pm 3 \%$ of baseline, $n=4$; dark-reared plus APV: $90 \pm 2 \%$ of baseline, $n=5$; $p<0.01$; Fig. $3 A$ ). However, the magnitude of synaptic depression evoked by $1 \mathrm{~Hz}$ stimulation in dark-reared rats was increased when APV was applied during low-frequency stimulation (dark-reared: $87 \pm 2 \%$ of baseline, $n=9$; dark-reared plus APV: $78 \pm 3 \%$ of baseline, $n=9 ; p<0.02$; Fig. $3 B)$. There is a clear qualitative difference in the effect of subsaturating APV on 1 
$A_{1}$

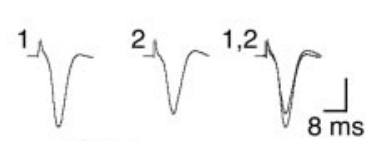

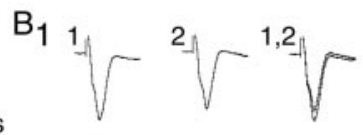

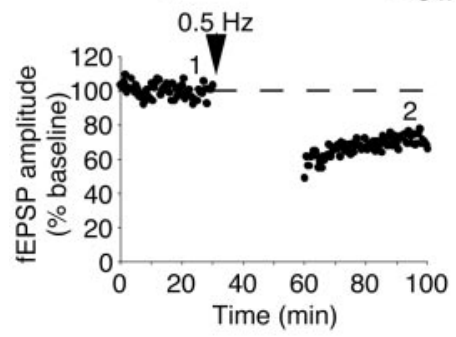

$\mathrm{A}_{2}$
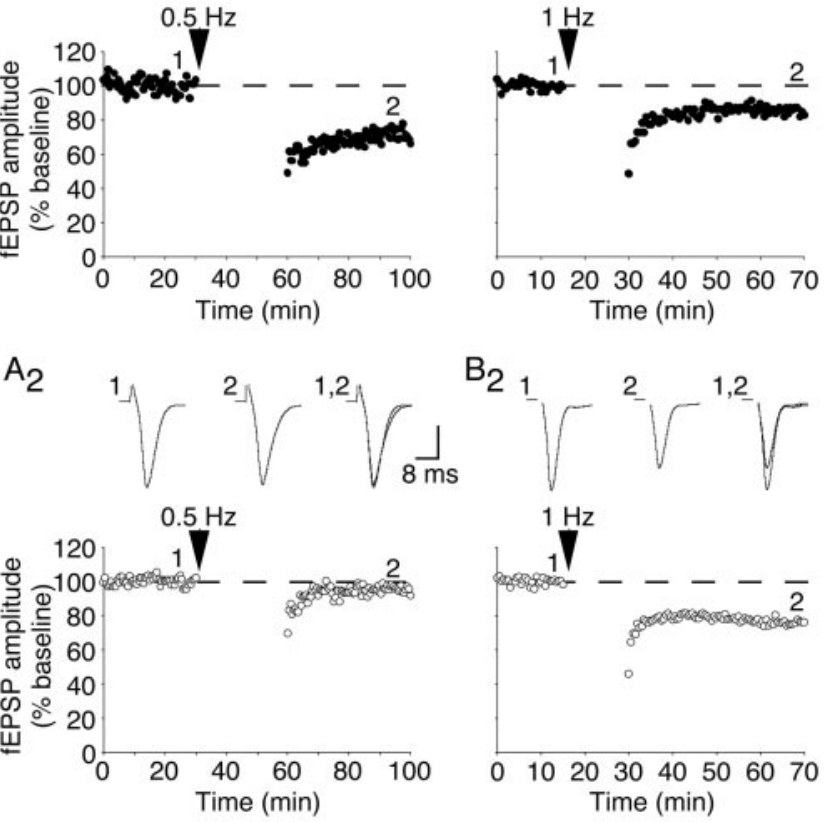

$\mathrm{A}_{3}$

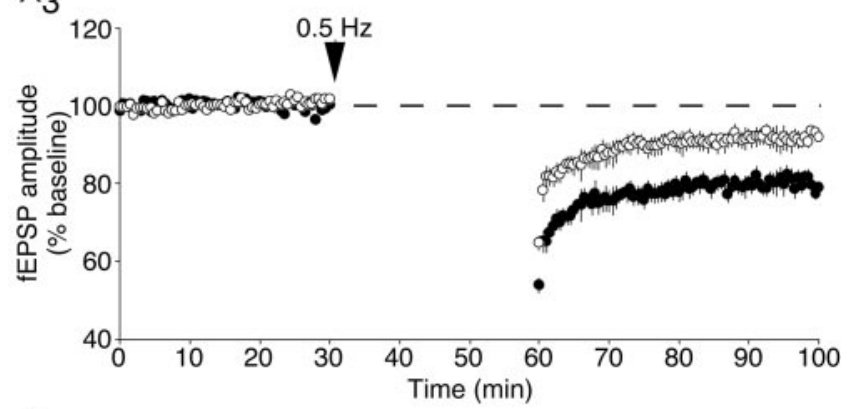

$\mathrm{B}_{3}$

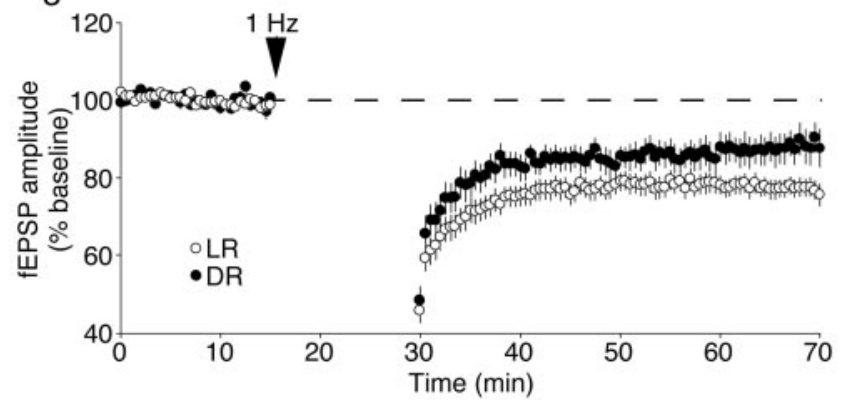

Figure 2. Dark-rearing exerts a horizontal shift in the frequency-response function; the magnitude of LTD is greater in dark-reared cortex than normal cortex with $0.5 \mathrm{~Hz}$ stimulation, whereas the converse is true with $1 \mathrm{~Hz}$ stimulation. $A$, Representative experiments $\left(A_{1}, A_{2}\right)$ and summary graph $\left(A_{3}\right)$ demonstrating the effects of a 30 min, $0.5 \mathrm{~Hz}$ stimulation on $\mathrm{FP}$ amplitude in dark-reared cortex $\left(A_{1}\right)$ and light-reared cortex $\left(A_{2}\right) . B$, Representative experiments $\left(B_{1}, B_{2}\right)$ and summary graph $\left(B_{3}\right)$ demonstrating the consequence of a $15 \mathrm{~min}, 1 \mathrm{~Hz}$ stimulation. DR, Dark-reared; $L R$, light-reared. Vertical scale bar, $0.4 \mathrm{mV}\left(A_{1}, A_{2}, B_{2}\right)$ or $0.2 \mathrm{mV}\left(B_{1}\right)$.

Hz LTD in light-reared and dark-reared animals, because the magnitude of $1 \mathrm{~Hz}$ LTD in light-reared animals was attenuated by $1 \mu \mathrm{M}$ APV (data not shown; $p<0.03$ ). Because the magnitude of LTD induced by low-frequency stimulations in normal cortex is similar to that of deprived cortex in the presence of $1 \mu \mathrm{M} \mathrm{APV}$, these data demonstrate that the light-reared LTD phenotype can

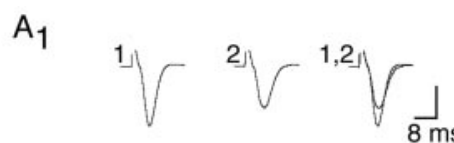

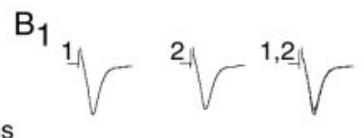
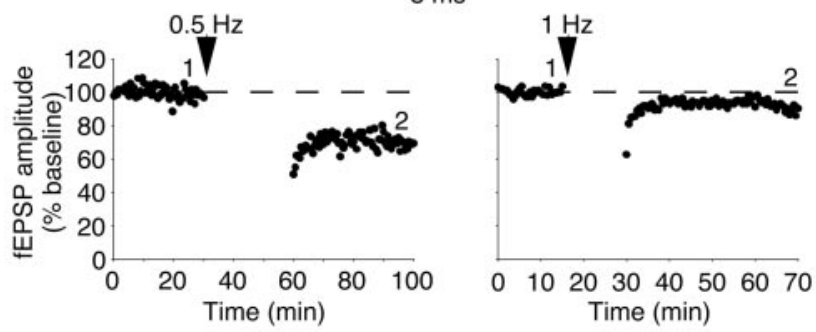

$\mathrm{A}_{2}$
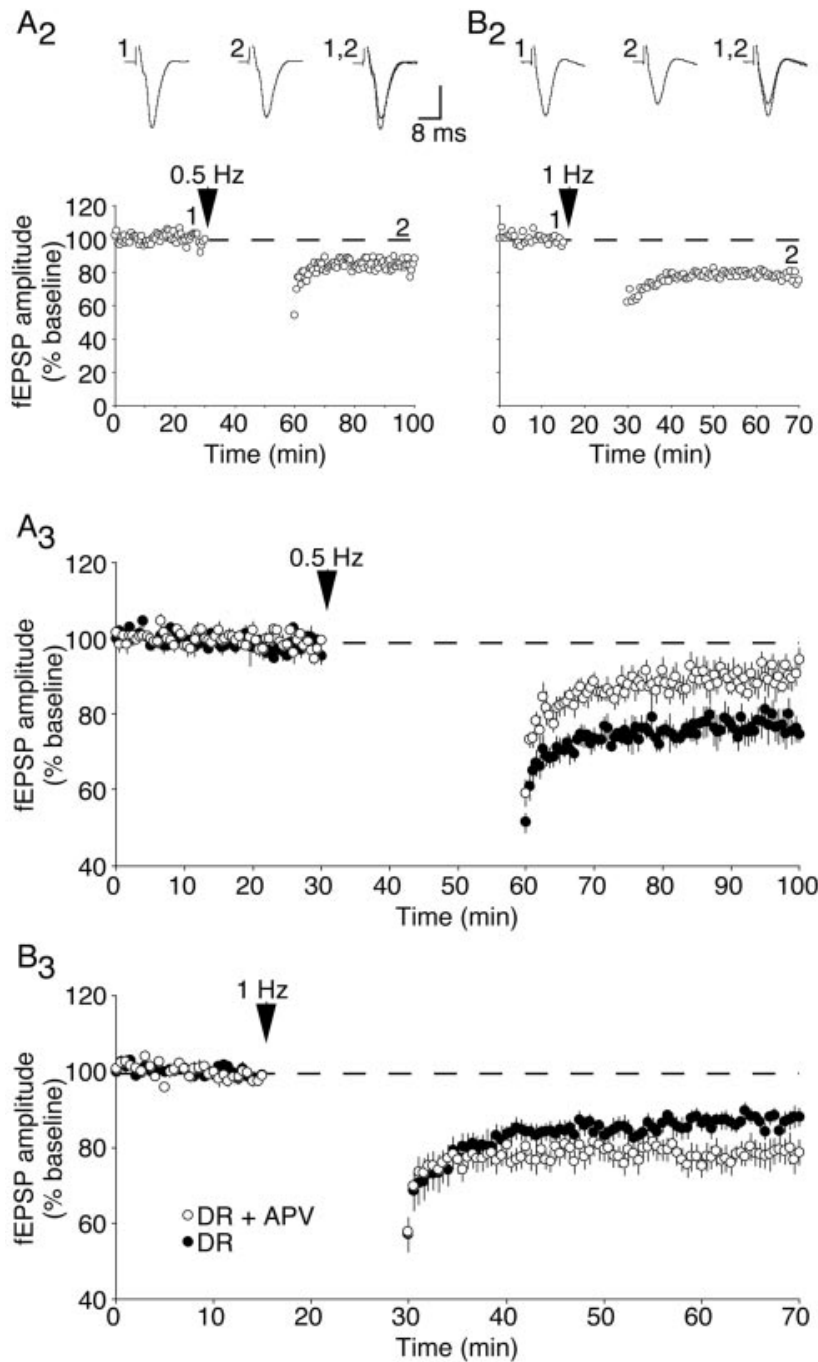

Figure 3. Partial NMDA receptor blockade in deprived cortical slices alters the properties of synaptic depression. $A$, Representative experiments $\left(A_{1}, A_{2}\right)$ and summary graph $\left(A_{3}\right)$ demonstrating the effects of a $30 \mathrm{~min}, 0.5 \mathrm{~Hz}$ stimulation on FP amplitude in dark-reared cortex $\left(A_{1}\right)$ and dark-reared cortex treated with $1 \mu \mathrm{M} \operatorname{APV}\left(A_{2}\right)$. B, Representative experiments $\left(B_{1}, B_{2}\right)$ and summary graph $\left(B_{3}\right)$ demonstrating the consequence of a $15 \mathrm{~min}, 1 \mathrm{~Hz}$ stimulation. DR, Darkreared; DR+APV, dark-reared $+1 \mu \mathrm{M}$ APV. Vertical scale bar, $0.4 \mathrm{mV}$.

be mimicked if NMDA receptor function is partially blocked in the visual cortex of dark-reared rats.

Effects of brief LE on LTD induced by

low-frequency stimulations

One way in which experience can modify NMDA receptor function is via changes in the receptor subunit composition. Previous 
studies have shown that the subunit composition of NMDA receptors is modified such that EPSCs are prolonged in the visual cortex of dark-reared rats. Moreover, only $2 \mathrm{hr}$ of LE are required to shorten NMDA receptor current durations to values observed in light-reared rats (Quinlan et al., 1999; Philpot et al., 2001a). If this change in NMDA receptor function underlies the observed metaplasticity of LTD, we predict that $2 \mathrm{hr}$ of LE should be sufficient to reverse the effects of dark-rearing on the frequencyresponse function. Consistent with this hypothesis, exposing dark-reared rats briefly to light decreased the magnitude of LTD evoked by $0.5 \mathrm{~Hz}$ stimulation (dark-reared: $80 \pm 2 \%$ of baseline, $n=6$; dark-reared plus $2 \mathrm{hr}$ LE: $90 \pm 3 \%$ of baseline, $n=5 ; p<$ 0.03; Fig. $4 A$ ) and increased the level of LTD evoked by $1 \mathrm{~Hz}$ stimulation (dark-reared: $86 \pm 3 \%$ of baseline, $n=9$; darkreared plus $2 \mathrm{hrLE}$ : $75 \pm 5 \%$ of baseline, $n=9$; $p<0.05$; Fig. $4 B$ ). Thus, brief LE of dark-reared rats can rapidly alter the properties of synaptic depression, restoring the light-reared LTD phenotype.

\section{Comparison of LTD across experimental conditions}

Although we ran separate interleaved dark-reared subjects for each of the three experiments, we successfully replicated the magnitude of LTD observed in dark-reared visual cortex with 0.5 and $1 \mathrm{~Hz}$ stimulation across experiments (Fig. 5A). Because there were no differences in the magnitude of LTD in dark-reared cortex, we have collapsed the dark-reared data across these experiments for presentation purposes (Fig. $5 B$ ). In summary, the magnitude of LTD evoked by $0.5 \mathrm{~Hz}$ stimulation is greater in darkreared rats compared with light-reared rats. Either brief LE or treatment with subsaturating concentrations of APV is sufficient to restore the light-reared phenotype in dark-reared rats. In contrast, LTD induced by $1 \mathrm{~Hz}$ stimulation is attenuated in darkreared rats compared with light-reared rats. Again, either LE or treatment of slices with subsaturating levels of APV is sufficient to drive dark-reared cortex toward the light-reared phenotype. Importantly, dark-reared cortex can express substantial levels of synaptic depression, because the level of LTD with $0.5 \mathrm{~Hz}$ stimulation in deprived cortex is similar to the level observed with $1 \mathrm{~Hz}$ stimulation in normal cortex.

\section{Discussion}

Kirkwood et al. (1996) previously showed that $1 \mathrm{~Hz}$ stimulation induces less LTD and depotentiation in the visual cortex from dark-reared animals as compared with normally reared controls. Because $1 \mathrm{~Hz}$ stimulation is normally very effective at producing synaptic depression, an obvious conclusion from these data is that the mechanism of LTD is impaired in dark-reared cortex. An alternative hypothesis, which our data now support, is that sensory deprivation impairs the recruitment of LTD with $1 \mathrm{~Hz}$ stimulation but that substantial synaptic depression can still be induced using a stimulation protocol that normally is suboptimal for LTD (e.g., $0.5 \mathrm{~Hz}$ stimulation).

What mechanism might be responsible for the shift in the properties of synaptic plasticity? Theoretical and experimental studies have suggested a number of ways in which plasticity might be regulated. For example, the properties of synaptic plasticity can be regulated by adjusting inhibitory tone, growth factor expression, or levels of free calmodulin (Huber et al., 1998; Steele and Mauk, 1999; Ikegaya et al., 2002; Krucker et al., 2002). Because the induction of LTP and LTD both require calcium entry through NMDA receptors, another obvious candidate for regulating plasticity is by modifying NMDA receptor function directly (Bear et al., 1987). Indeed,

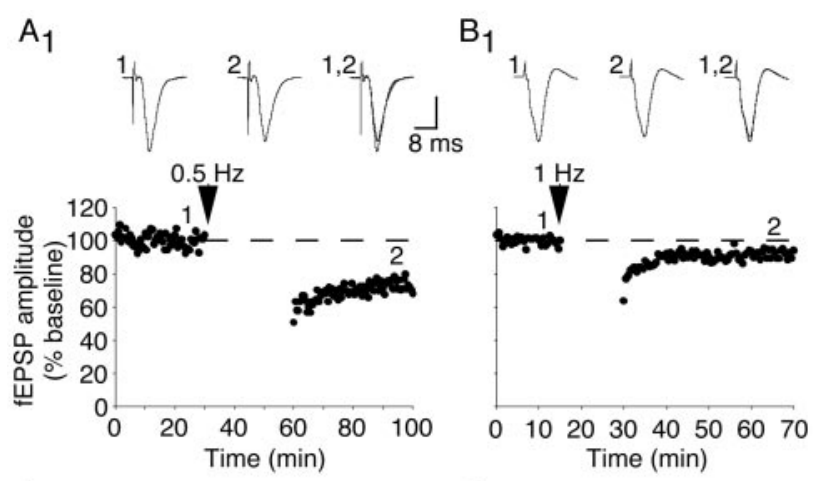

$\mathrm{A}_{2}$

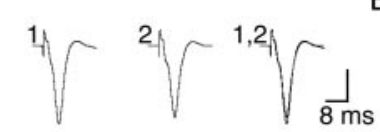

$\mathrm{B}_{2}$
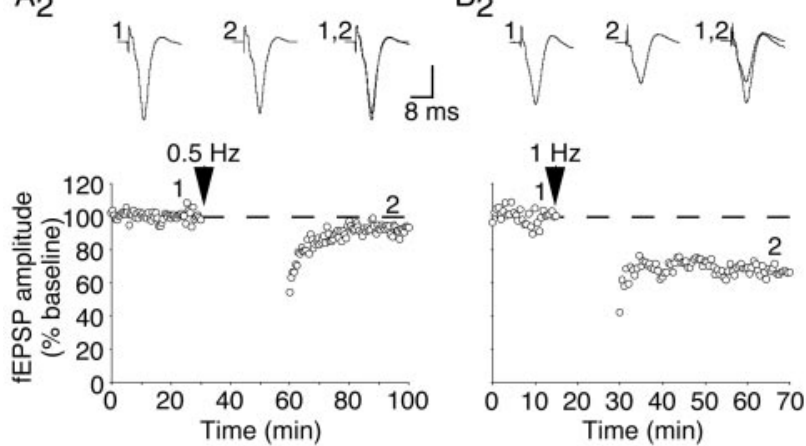

$\mathrm{A}_{3}$

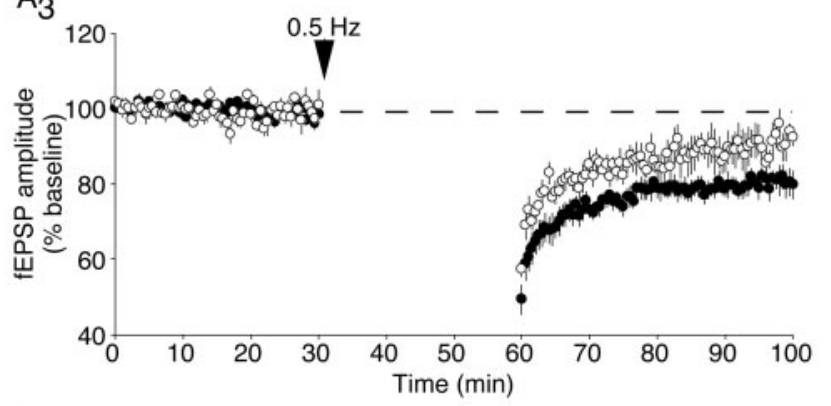

$\mathrm{B}_{3}$

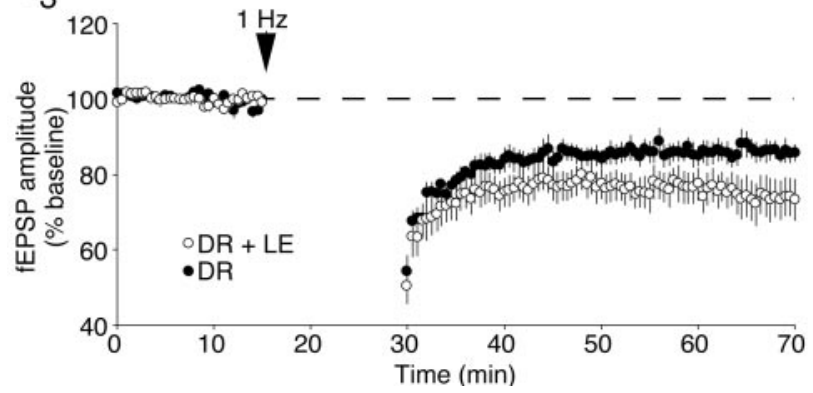

Figure 4. Brief $L E(2 \mathrm{hr})$ modifies the induction of $L T D$ with low-frequency stimulations. $A$, Representative experiments $\left(A_{1}, A_{2}\right)$ and summary graph $\left(A_{3}\right)$ demonstrating the effects of a 30 min, $0.5 \mathrm{~Hz}$ stimulation on FP amplitude in dark-reared cortex $\left(A_{1}\right)$ and cortex from darkreared animals given brief $L E\left(A_{2}\right)$. $B$, Representative experiments $\left(B_{1}, B_{2}\right)$ and summary graph $\left(B_{3}\right)$ demonstrating the consequence of a $15 \mathrm{~min}, 1 \mathrm{~Hz}$ stimulation. DR, Dark-reared; $L E$, lightexposed. Vertical scale bar $=0.4 \mathrm{mV}\left(A_{2}, B_{1}, B_{2}\right)$ or $0.2 \mathrm{mV}(A 1)$.

stimulation protocols that normally induce LTP in CA1 of the hippocampus can induce LTD when NMDA receptor activation is attenuated by subsaturating concentrations of APV (Cummings et al., 1996). Accumulating evidence suggests that experience-dependent modifications in NMDA receptor function in the visual cortex might regulate the properties of synaptic plasticity (Tsumoto et al., 1987; Fox et al., 1991; Car- 
A
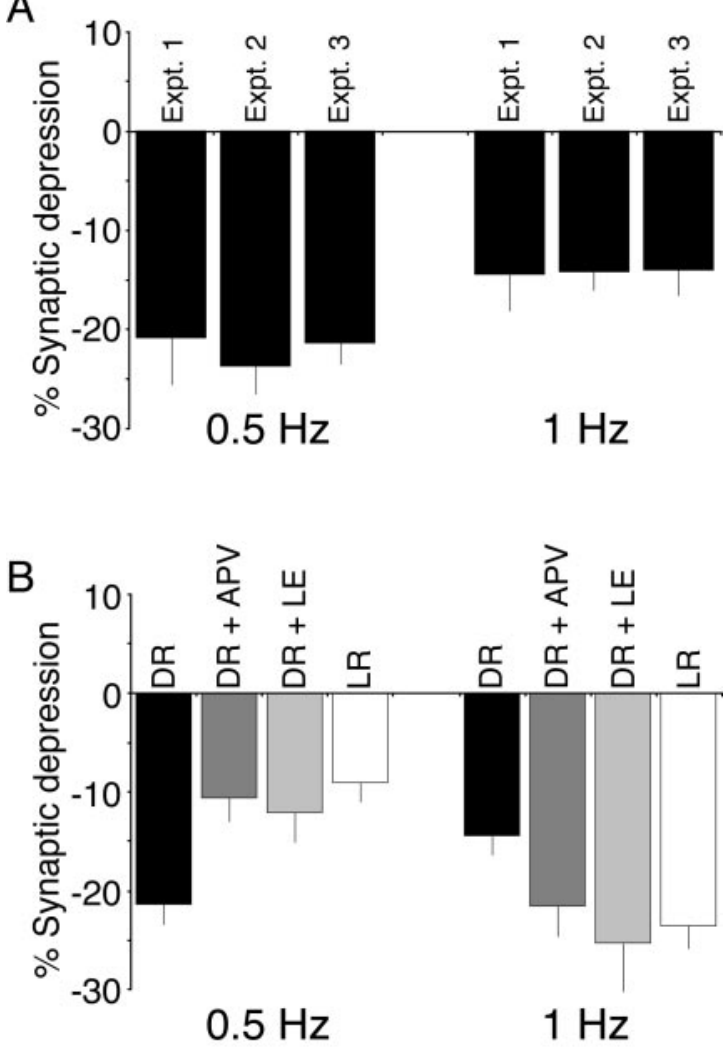

Figure 5. Summary demonstrating that the light-reared LTD phenotype can be mimicked either by partially blocking NMDA receptor function in dark-reared visual cortex or by briefly exposing dark-reared animals to light (a procedure known to shorten NMDA receptor currents). $A$, The magnitude of synaptic depression induced by 0.5 or $1 \mathrm{~Hz}$ stimulation in dark-reared cortex can be reproduced across experiments. $B$, Summary graphs demonstrating the average magnitude ( \pm SEM) of synaptic depression induced by 0.5 or $1 \mathrm{~Hz}$ stimulation in dark-reared (DR) cortex, APV-treated DR cortex (DR + APV), light-exposed DR cortex (DR + LE), and light-reared (LR) cortex. Dark-reared values represent averaged data across all three experiments.

mignoto and Vicini, 1992; Quinlan et al., 1999; Philpot et al., 2001a). The present study now provides two additional lines of evidence. First, the properties of LTD in normal cortex can be mimicked in deprived cortex by partially blocking NMDA receptor function, consistent with the idea that NMDA receptor function is enhanced in the cortex of dark-reared rats. Second, briefly exposing a dark-reared animal to $2 \mathrm{hr}$ of light can also restore the light-reared LTD phenotype. Because brief LE shortens NMDA receptor current durations recorded in layer 2/3 pyramidal cells (Philpot et al., 2001a), the reduction in NMDA receptor current duration might underlie the observed change in the properties of LTD. Taken together, these data suggest that visual experience reduces NMDA receptor function by decreasing the number of synaptic NMDA receptors and/or by shortening the NMDA receptor-mediated EPSC, resulting in a rightward shift in the frequency-response function.

Although the correlation between the experience-driven shift in LTD properties and NMDA receptor current durations is impressive, it is interesting to consider how changing current duration could affect the induction of LTD with lowfrequency stimulation. The impact of modestly longer current durations clearly becomes manifest with high-frequency stim- ulation, because longer currents promote greater temporal summation and, thus, calcium entry into the cell (Philpot et al., 2001a; Philpot et al., 2001b). However, changes in temporal summation of synaptic currents alone cannot account for observed differences in LTD between normal and deprived cortex. For temporal summation to take place with $0.5 \mathrm{~Hz}$ stimulation, NMDA currents must have a duration of $2 \mathrm{sec}$ or greater. However, measured NMDA receptor EPSCs in the visual cortex do not approach this duration. A simple solution to this paradox is to assume that $\mathrm{Ca}^{2+}$ clearance from the synapse during low-frequency stimulation has a slow time course, thus amplifying the consequences of relatively small changes in current duration (Connor and Cormier, 2000). Indeed, a recent theoretical study of calcium-dependent bidirectional synaptic plasticity was able to reproduce the observed horizontal shift in the frequency-response function solely by altered NMDA receptor EPSC kinetics, if it was assumed that calcium signals relevant for synaptic plasticity integrate more slowly than the EPSCs (Shouval et al., 2002). Of course, regulating this calcium integration parameter (e.g., by altering spine geometry or calcium buffer capacity) offers yet another potential mechanism for the observed metaplasticity in the visual cortex (Gold and Bear, 1994).

\section{References}

Bear MF (1998) The role of LTD and LTP in development and learning. In: Mechanistic relationships between development and learning (Carew TJ, Menzel R, Shatz CJ, eds), pp 205-225. New York: Wiley.

Bear MF, Abraham WC (1996) Long-term depression in hippocampus. Annu Rev Neurosci 19:437-462.

Bear MF, Cooper LN, Ebner FF (1987) A physiological basis for a theory of synaptic modification. Science 237:42-48.

Carmignoto G, Vicini S (1992) Activity-dependent decrease in NMDA receptor responses during development of the visual cortex. Science 258:1007-1011.

Castellani GC, Quinlan EM, Cooper LN, Shouval HZ (2001) A biophysical model of bidirectional synaptic plasticity: dependence on AMPA and NMDA receptors. Proc Natl Acad Sci USA 98:12772-12777.

Connor JA, Cormier RJ (2000) Cumulative effects of glutamate microstimulation on $\mathrm{Ca}^{(2+)}$ responses of CA1 hippocampal pyramidal neurons in slice. J Neurophysiol 83:90-98.

Cummings JA, Mulkey RM, Nicoll RA, Malenka RC (1996) $\mathrm{Ca}^{2+}$ signalling requirements for long-term depression in the hippocampus. Neuron 16:825-833.

Fox K, Daw N, Sato H, Czepita D (1991) Dark-rearing delays the loss of NMDA-receptor function in kitten visual cortex. Nature 350:342-344

Gold J, Bear M (1994) A model of dendritic spine $\mathrm{Ca}^{2+}$ concentration exploring possible bases for a sliding modification threshold. Proc Natl Acad Sci USA 91:3941-3945.

Huber KM, Sawtell NB, Bear MF (1998) Brain-derived neurotrophic factor alters the synaptic modification threshold in visual cortex. Neuropharmacology 37:571-579.

Ikegaya Y, Ishizaka Y, Matsuki N (2002) BDNF attenuates hippocampal LTD via activation of phospholipase C: implications for a vertical shift in the frequency-response curve of synaptic plasticity. Eur J Neurosci 16:145-148.

Katz LC, Shatz CJ (1996) Synaptic activity and the construction of cortical circuits. Science 274:1133-1138.

Kirkwood A, Bear MF (1994) Homosynaptic long-term depression in the visual cortex. J Neurosci 14:3404-3412.

Kirkwood A, Dudek SM, Gold JT, Aizenman CD, Bear MF (1993) Common forms of synaptic plasticity in the hippocampus and neocortex in vitro. Science 260:1518-1521.

Kirkwood A, Rioult MG, Bear MF (1996) Experience-dependent modification of synaptic plasticity in visual cortex. Nature 381:526-528.

Krucker T, Siggins GR, McNamara RK, Lindsley KA, Dao A, Allison DW, De Lecea L, Lovenberg TW, Sutcliffe JG, Gerendasy DD (2002) Targeted 
disruption of RC3 reveals a calmodulin-based mechanism for regulating metaplasticity in the hippocampus. J Neurosci 22:5525-5535.

Mulkey RM, Endo S, Shenolikar S, Malenka RC (1994) Involvement of a calcineurin/inhibitor-1 phosphatase cascade in hippocampal long-term depression. Nature 369:486-488.

Neveu D, Zucker RS (1996) Postsynaptic levels of $\left[\mathrm{Ca}^{2+}\right]$ i needed to trigger LTD and LTP. Neuron 16:619-629.

Ngezahayo A, Schachner M, Artola A (2000) Synaptic activity modulates the induction of bidirectional synaptic changes in adult mouse hippocampus. J Neurosci 20:2451-2458.

Philpot BD, Sekhar AK, Shouval HZ, Bear MF (2001a) Visual experience and deprivation bidirectionally modify the composition and function of NMDA receptors in visual cortex. Neuron 29:157-169.

Philpot BD, Weisberg MP, Ramos MS, Sawtell NB, Tang YP, Tsien JZ, Bear
MF (2001b) Effect of transgenic overexpression of NR2B on NMDA receptor function and synaptic plasticity in visual cortex. Neuropharmacology 41:762-770.

Quinlan EM, Philpot BD, Huganir RL, Bear MF (1999) Rapid, experiencedependent expression of synaptic NMDA receptors in visual cortex in vivo. Nat Neurosci 2:352-357.

Shouval HZ, Bear MF, Cooper LN (2002) A unified model of NMDA receptor-dependent bidirectional synaptic plasticity. Proc Natl Acad Sci USA 99:10831-10836.

Steele PM, Mauk MD (1999) Inhibitory control of LTP and LTD: stability of synapse strength. J Neurophysiol 81:1559-1566.

Tsumoto T, Hagihara K, Sato H, Hata Y (1987) NMDA receptors in the visual cortex of young kittens are more effective than those of adult cats. Nature 327:513-514. 